\title{
Integrative Medicine and Ageing
}

\author{
Michael Teut Miriam Ortiz \\ Institut für Sozialmedizin, Epidemiologie und Gesundheitsökonomie, Charité Universitätsmedizin Berlin, \\ corporate member of Freie Universität Berlin and Humboldt-Universität zu Berlin, Berlin, Germany
}

\section{Keywords}

Integrative medicine · Ageing · Older adults · Geriatrics

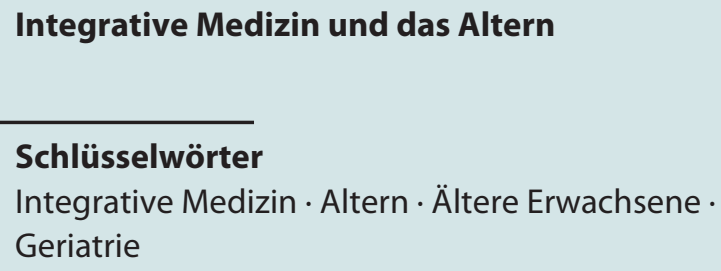

According to the World Health Organization (WHO), demographic ageing of societies, along with climate change and infectious diseases with microbial resistance development, represents one of the greatest health challenges of the modern era [1]. The global population of adults aged 65 years and older is expected to grow from an estimated 524 million in 2010 to 1.5 billion by 2050 [2]

The WHO believes comprehensive public health interventions are needed to address the societal and health changes caused by ageing and to adapt health systems accordingly. The WHO calls for a broadening of the perspective from causal therapy of individual disease entities to a more holistic approach that focuses on the personality of the older person and his or her needs [1]. To this end, the WHO has proclaimed 2021 to 2030 the "UN Decade of Healthy Ageing" in which civil societies, international agencies, professionals, academia, the media, and the private sector will spend 10 years developing and improving concerted, catalytic, and collaborative actions to improve the lives of older people, their families, and the communities in which they live [3].
In 1997, ageing researchers Rowe and Kahn initiated a shift in thinking about ageing medicine with their paper "Successful Ageing" [4]. Whereas successful ageing had previously been understood as an adaptation of elderly people to the functional losses and stresses that occur with age, they proposed a model that is positively oriented and includes biological and psychological aspects. According to this model, successful ageing does not consist solely of the absence of illness or coping with age-related changes but rather of three factors that are mutually dependent and reinforcing:

1 minimizing the risk of disease and disability;

2 high levels of physical and cognitive functioning;

3 active engagement with life.

Rowe and Kahn thus emphasize the shapeability of ageing; through healthy lifestyles, mental and physical activity, active engagement, social relationships, physical and mental training, and learning and education, health can be promoted in advanced age, thus shaping a successful, more fulfilling and healthier ageing population.

Futurologist Frank Ruff interprets ageing of the future as a "subjectively malleable reality" that is about "self-design," "longevity," "regeneration," and "resource management" [5].

The influence of genetics on the ageing process of humans is assumed to be $20-30 \%$ but increases significantly with longevity, as known from twin studies [6]: ageing is strongly influenced by genetics, but the larger part of ageing can be influenced and shaped by lifestyle factors and prevention.

The concept of integrative medicine offers a holistic perspective that fits well with the modern view of geriatrics [7]. Many integrative or complementary therapy 
strategies target primary or tertiary prevention and operate from a systemic perspective. This is particularly true of complex (whole) therapeutic systems, such as European Kneipp therapy, Ayurveda, Tibetan medicine, Unani, or Traditional Chinese Medicine, in which lifestyle, diet, exercise, psychological therapies, manual (and reflex) therapies, and natural remedies are combined, often within the framework of a distinct theory of health and disease.

The WHO identifies three geriatric target groups that would benefit from interventions. Target group 1 includes older people who have stable health. Here, the goals are to improve health-promoting behaviours, selfcare, prevention, and early detection of disease. In other words, interventions for this group would support healthy ageing. In the following paragraphs, integrative medicine strategies for this target group are presented.

\section{Nutrition}

The concept of whole food nutrition, including vegetarian and vegan diets (when deficiencies are avoided), and especially the concept of the Mediterranean diet, is based on a high proportion of plant-based foods. The risk of many chronic diseases, especially coronary heart disease, stroke, diabetes mellitus, and cancer, is reduced by this approach [8-11]. In addition, by eating less meat and more plant-based diets, we also make a relevant contribution to climate protection.

\section{Caloric Restriction}

In antiaging research, caloric restriction is a "hot topic." Extensive laboratory and animal studies have found that limiting calories in the diets of yeast, flies, worms, mice, rats, and even monkeys leads to better health and longer life spans [12]. A 30\% reduction in calories led to significant reductions in adult-onset diabetes, cardiovascular diseases, and cancer and decreases in markers of ageing in monkeys [13-16]. Health benefits have also been demonstrated in humans, but although life-prolonging effects seem theoretically plausible, they have not yet been proven $[17,18]$. With fasting, integrative medicine has a traditional strategy of caloric restriction that is used in many cultures and has already shown many health benefits [19]. Future studies will show the extent to which different forms of fasting, including intermittent fasting, have positive influences on ageing, morbidity, and mortality. Caloric restriction is not indicated for elderly people with malnutrition, eating disorders, frailty, and cachexia but is particularly suitable for normal- to overweight older persons with stable health.

\section{Anti-Ageing Substances}

For decades, anti-ageing researchers have been searching for various natural substances that could positively affect ageing. However, there have been disappointments over the decades, such as with resveratrol from red wine. Evidence currently tends to favour more complex interventions (e.g., caloric restriction, the Mediterranean diet) rather than single medically effective substances. The scientific focus is currently on polyphenol-rich plants such as green tea, olive oil, and curcuma. It remains to be seen to what extent this (and other approaches from conventional pharmacological research) will lead to effective and useful medical anti-ageing approaches in the future. From an integrative medicine perspective, focusing only on individual drugs seems reductionist.

\section{Exercise and Sports}

Exercise interventions are among the most important interventions for successful and healthy ageing. Regular exercise prolongs life and reduces the risk of chronic diseases $[20,21]$. It prevents, delays, and treats a variety of chronic diseases and can prevent or delay the onset of frailty in old age $[22,23]$. The WHO recommends more than $150 \mathrm{~min}$ of moderate endurance exercise or $75 \mathrm{~min}$ of vigorous endurance exercise per week. Of particular interest in the context of integrative medicine is moderate physical activity, such as walking, hiking, swimming, and cycling (especially in natural environments). Special movement therapies such as eurythmy, yoga, qigong, and tai chi can also be considered and explored.

\section{Meditation, Mindfulness, and Relaxation}

Several studies are currently investigating the extent to which meditation, mindfulness, and relaxation might have a positive impact on the health of older adults and ageing, particularly on the prevention of degenerative brain diseases. These mind-body strategies may positively contribute to cognitive fitness and well-being in ageing [24-26].

Many of these therapeutic strategies can also be applied to the WHO's second target population: elderly patients who are experiencing declines or reductions in health capacity. Here, the goal is to reverse age-related decline and improve the functional capabilities of those affected.

The third WHO target group is patients with a severe reduction in health capacities. With this group, the goal is to achieve a life with dignity and to provide effective medical assistance for the treatment of chronic diseases. Here, integrative and palliative nursing care, physiotherapy, devotion, and medication support are particularly needed. 
A special challenge is the increasing number of patients with dementia and their therapy and care. The German S3 guidelines on dementia emphasize the importance of non-pharmacological treatments [27], including psychosocial activities in combination with physical, sensory, and mental training and occupational therapy together with an individual resource-fostering attitude ( $b a-$ sale Stimulation) [28]. In particular, behavioural symptoms in dementia should be treated with physical activity, memory training, and occupational training, and aromatherapy and music therapy may also be considered [29]. The stabilizing effects of a multimodal approach consisting of motor stimulation, practice in activities of daily living and cognitive stimulation on the outcomes of activities of daily living, social behaviours, and cognition have been shown in randomized controlled studies in nursing home residents with dementia [30,31].

\section{Perspectives}

Integrative medicine could contribute significantly to successful and healthy ageing but is not a well-researched approach in geriatric diseases. Integrative medicine in theory and practice with its therapeutic elements and conceptionally anchored multimodality fits well with geriatric strategies to promote healthy and successful ageing. As part of the UN Decade of Healthy Ageing, integrative medicine physicians, therapists, and researchers are called upon and encouraged to get involved in promoting healthy ageing. There are many opportunities for the application and research of integrative medicine.

\section{Conflict of Interest Statement}

The authors have no conflicts of interest to declare.

\section{Funding Sources}

No funding was received for this paper.

\section{Author Contributions}

M.T. conceptualized and M.O. and M.T. wrote the paper.

\section{References}

1 World Health Organization. World report on ageing and health. 2015 [cited 2021 Jun 29]. Available from: https://www.who.int/ageing/ publications/world-report-2015/en/.

2 National Institute on Aging, National Institutes of Health, US Department of Health and Human Services, World Health Organization. Global health and aging. 2011 [cited 2021 Jun 29]. Available from: http://www. who.int/ageing/publications/global_health. pdf.

3 World Health Organization. Decade of healthy ageing [cited 2021 Jun 29]. Available from: https://www.who.int/initiatives/decade-of-healthy-ageing.

4 Rowe JW, Kahn RL. Successful aging. Gerontologist. 1997 Aug;37(4):433-40.

5 Ruff F. Perspektiven zum künftigen Wandel gesellschaftlicher (Leit-)Bilder des Alterns. In: Kocka J, Staudinger UM, editors. Altern in Deutschland. Vol 1. Nova Acta Leopoldina NF 99; 363, Deutsche Akademie der Naturforscher Leopoldina. Stuttgart: Wissenschaftliche Verlagsgesellschaft; 2009. p. 17390.

6 Sebastiani P, Nussbaum L, Andersen SL, Black MJ, Perls TT. Increasing Sibling Relative Risk of Survival to Older and Older Ages and the Importance of Precise Definitions of "Aging," "Life Span," and "Longevity." J Gerontol A Biol Sci Med Sci. 2016 Mar;71(3): 340-6.

7 Teut M, Ortiz M. Integrative Medizin in der Altersheilkunde. In: Brinkhaus B, Esch T, editors. Integrative Medizin und Gesundheit.
Berlin: Medizinisch Wissenschaftliche Verlagsgesellschaft; 2021.

8 Aune D, Giovannucci E, Boffetta P, Fadnes LT, Keum N, Norat T, et al. Fruit and vegetable intake and the risk of cardiovascular disease, total cancer and all-cause mortality - a systematic review and dose-response metaanalysis of prospective studies. Int J Epidemiol. 2017 Jun;46(3):1029-56.

9 Aune D. Plant Foods, Antioxidant Biomarkers, and the Risk of Cardiovascular Disease, Cancer, and Mortality: A Review of the Evidence. Adv Nutr. 2019 Nov;10 Suppl 4:S40421.

10 Mazzocchi A, Leone L, Agostoni C, PaliSchöll I. The Secrets of the Mediterranean Diet. Does [Only] Olive Oil Matter? Nutrients. 2019 Dec;11(12):2941.

11 Shannon OM, Ashor AW, Scialo F, Saretzki G, Martin-Ruiz C, Lara J, et al. Mediterranean diet and the hallmarks of ageing. Eur J Clin Nutr. 2021 Aug;75(8):1176-92.

12 Fontana L, Partridge L, Longo VD. Extending healthy life span - from yeast to humans. Science. 2010 Apr;328(5976):321-6.

13 Colman RJ, Anderson RM, Johnson SC, Kastman EK, Kosmatka KJ, Beasley TM, et al. Caloric restriction delays disease onset and mortality in rhesus monkeys. Science. 2009 Jul;325(5937):201-4.

14 Colman RJ, Beasley TM, Kemnitz JW, Johnson SC, Weindruch R, Anderson RM. Caloric restriction reduces age-related and all-cause mortality in rhesus monkeys. Nat Commun. 2014 Apr;5(1):3557.
15 Mattison JA, Colman RJ, Beasley TM, Allison DB, Kemnitz JW, Roth GS, et al. Caloric restriction improves health and survival of rhesus monkeys. Nat Commun. 2017 Jan;8(1): 14063.

16 Rhoads TW, Clark JP, Gustafson GE, Miller KN, Conklin MW, DeMuth TM, et al. Molecular and Functional Networks Linked to Sarcopenia Prevention by Caloric Restriction in Rhesus Monkeys. Cell Syst. 2020 Feb;10(2):156-168.e5.

17 Most J, Tosti V, Redman LM, Fontana L. Calorie restriction in humans: an update. Ageing Res Rev. 2017 Oct;39:36-45.

18 Kökten T, Hansmannel F, Ndiaye NC, Heba AC, Quilliot D, Dreumont N, et al. Calorie restriction as a new treatment of inflammatory diseases. Adv Nutr. 2021 Jul;12(4):1558-70.

19 Boschmann M, Michalsen A. Fasting therapy - old and new perspectives. Forsch Komplement Med. 2013;20(6):410-1.

20 Hamer M, de Oliveira C, Demakakos P. Nonexercise physical activity and survival: English longitudinal study of ageing. Am J Prev Med. 2014 Oct;47(4):452-60.

21 Paterson DH, Jones GR, Rice CL. Ageing and physical activity: evidence to develop exercise recommendations for older adults. Can J Public Health. 2007;98 Suppl 2:S69-108.

22 Coelho-Júnior HJ, Uchida MC, Picca A, Bernabei R, Landi F, Calvani R, et al. Evidencebased recommendations for resistance and power training to prevent frailty in community-dwellers. Aging Clin Exp Res. 2021 Aug;33(8):2069-86. 
23 Pedersen BK, Saltin B. Exercise as medicine - evidence for prescribing exercise as therapy in 26 different chronic diseases. Scand J Med Sci Sports. 2015 Dec;25 Suppl 3:1-72.

24 Chételat G, Lutz A, Arenaza-Urquijo E, Collette F, Klimecki O, Marchant N. Why could meditation practice help promote mental health and well-being in aging? Alzheimers Res Ther. 2018 Jun;10(1):57.

25 Conklin QA, Crosswell AD, Saron CD, Epel ES. Meditation, stress processes, and telomere biology. Curr Opin Psychol. 2019 Aug;28:92101
26 Gard T, Hölzel BK, Lazar SW. The potential effects of meditation on age-related cognitive decline: a systematic review. Ann N Y Acad Sci. 2014 Jan;1307(1):89-103.

27 Deutsche Gesellschaft für Psychiatrie und Psychotherapie, Psychosomatik und Nervenheilkunde DGPPN, Deutsche Gesellschaft für Neurologie DGN. S3-Leitlinie "Demenzen." Langversion - Januar 2016. Available from: https://www.dgppn.de/fileadmin/user_upload/_medien/download/pdf/kurzversionleitlinien/S3-LL-Demenzen-240116-1.pdf.

28 Bienstein C, Fröhlich A. Basale Stimulation ${ }^{\circledR}$ in der Pflege - Die Grundlagen. Praxishandbuch. 9., vollständig überarbeitete und erweitere Aufl. Göttingen: Hogrefe; 2021.
29 Kratz T. The diagnosis and treatment of behavioral disorders in dementia. Dtsch Ärztebl Int. 2017 Jun;114(26):447-54.

30 Graessel E, Stemmer R, Eichenseer B, Pickel S, Donath C, Kornhuber J, et al. Non-pharmacological, multicomponent group therapy in patients with degenerative dementia: a 12-month randomizied, controlled trial. BMC Med. 2011 Dec;9(1):129.

31 Straubmeier M, Behrndt EM, Seidl H, Özbe D, Luttenberger K, Graessel E. Non-pharmacological treatment in people with cognitive impairment - results from the randomized controlled German Day Care Study. Dtsch Ärztebl Int. 2017 Dec;114(48):815-21. 